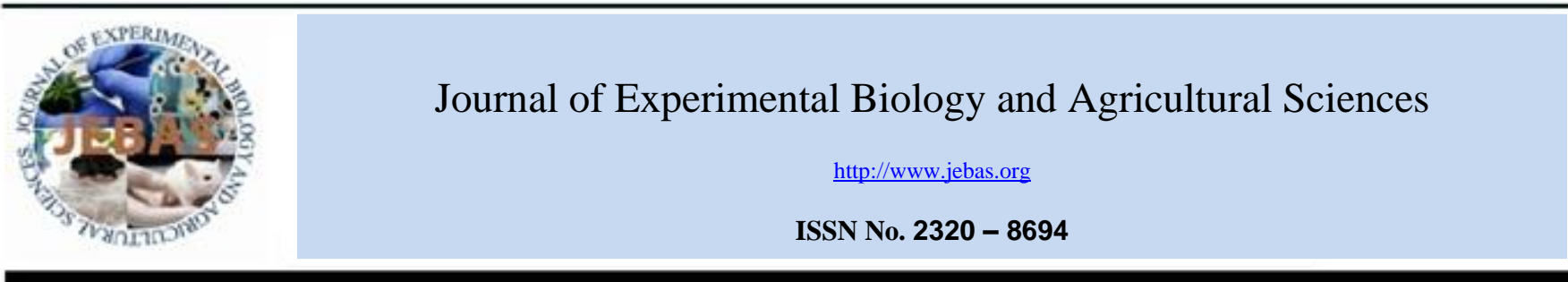

\title{
A HYPOTHETICAL DESIGN TO INHIBIT COVID 19 DISEASE DISASTER BY DIAGRAMMATIC MODEL
}

\section{Deepanwita Deka ${ }^{1 *}$, Avra Pratim Chowdhury $^{2 *}$, Arabinda Ghosh $^{3}$, Moni P Bhuyan $^{4}$}

\footnotetext{
${ }^{1 *}$ Department of Botany, S. B. Deorah College, Gauhati University, Guwahati, Assam, India.

$2^{2 *}$ Department of Botany, Gauhati University, Assam, India.

${ }^{3}$ Microbiology Division, Dept. of Botany, Gauhati University, Assam, India

${ }^{4}$ SRL Diagnostic Limited, Assam, India.
}

Received - January 24, 2021; Revision - May 22, 2021; Accepted - June 01, 2021

Available Online - June 25, 2021

DOI: http://dx.doi.org/10.18006/2021.9(3).311.324

\section{GRAPHICAL ABSTRACT}

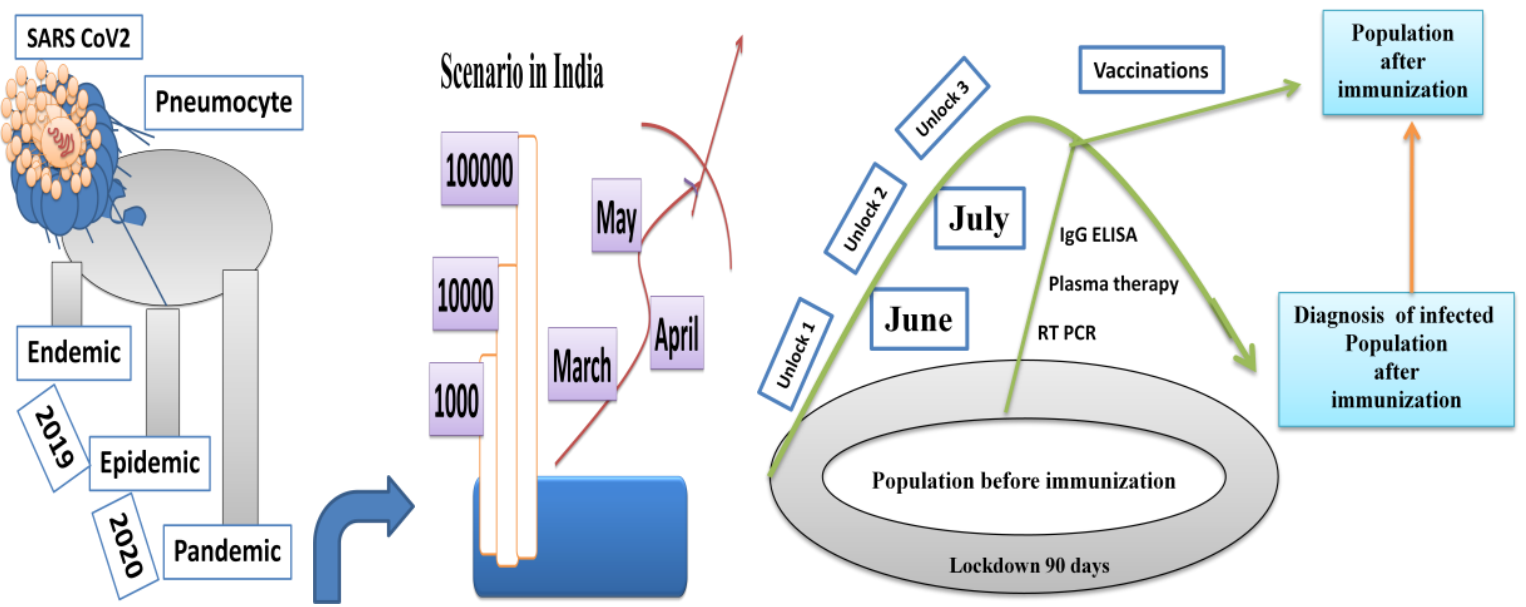

\section{* Corresponding author}

E-mail: deepanwita87@gmail.com (Deepanwita Deka),

avranu132@gmail.com, avranu132@gauhati.ac.in (Avra Pratim Chowdhury)

Peer review under responsibility of Journal of Experimental Biology and Agricultural Sciences.

Production and Hosting by Horizon Publisher India [HPI] (http://www.horizonpublisherindia.in/).

All rights reserved.
All the articles published by Journal of Experimental Biology and Agricultural Sciences are licensed under a Creative Commons Attribution-NonCommercial 4.0 International License Based on a work at www.jebas.org.

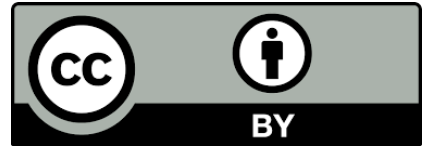




\section{Analysis on Control Management:}

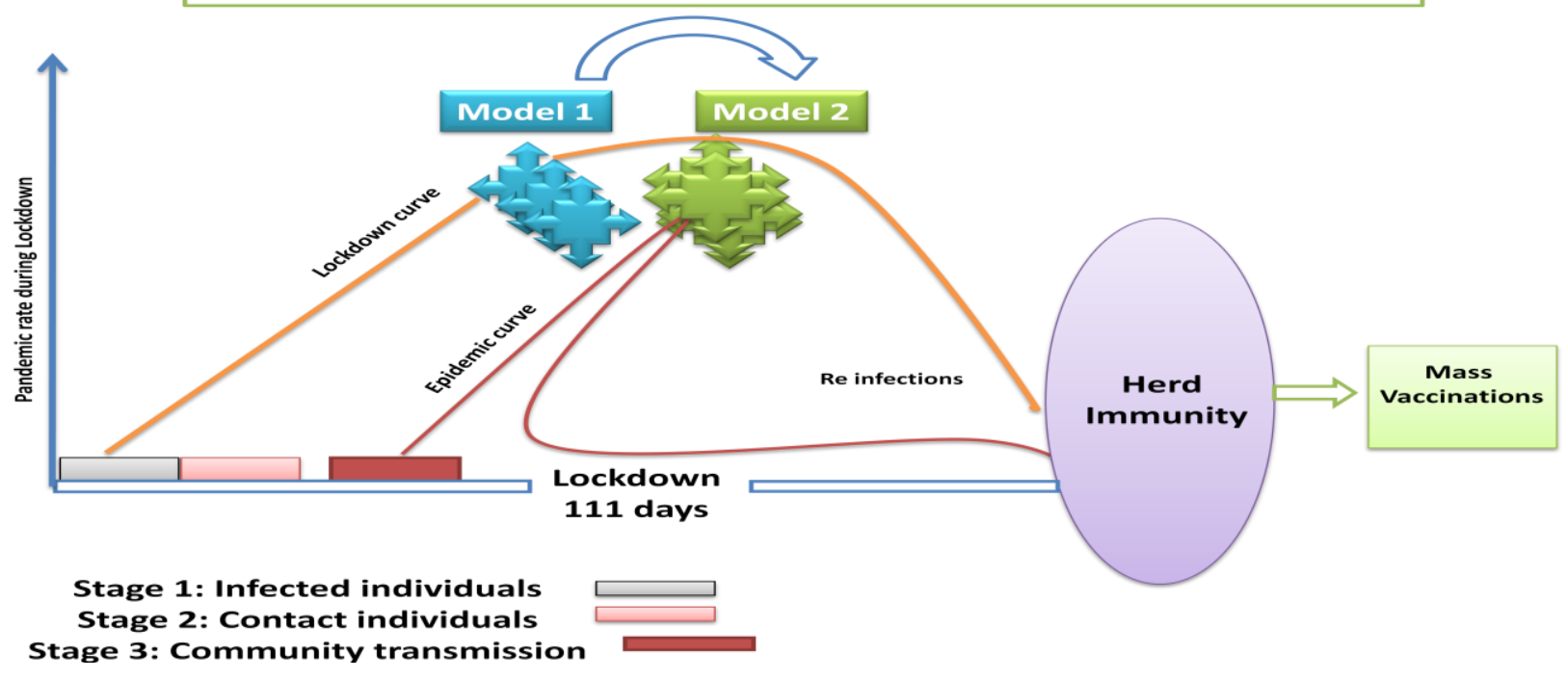

\section{KEYWORDS}

Disaster management

Hotspot

Lockdown

Quarantine

Vaccines

\section{Introduction}

India, the land of 3,287,240 sq. km maintained a population of 1.3 billion, is now faced with a great challenge with 55 catastrophic invasions (Bhatnagar et al., 2020). Indian states play the role of contributions to its economy as a harbor of powerhouses of GDP per year. The reported data were presented and shown to make follow-up on Delhi, Gujrat, West Bengal, Maharastra, Tamil Nadu, Madhya Pradesh, Rajasthan, crossed a hundred marks with more than 2500 cases in April 2020 (Roosa et al., 2020). At the beginning of May 2020, the increased impact was triggered by threatened concerns all over the states of India. The report on viral transmission was claimed by a model before COVID 19 submerged (Viboud et al., 2016; Kumar et al., 2018). Following this previous report likely Kerala was the first place to determine COVID 19 disaster and followed its health initials to stop its migration before community transmission. Maharashtra could not effort their restriction by following health measures that lead to progression up to more than 10,000 during May 2020. At this time there were few states of east and northern part of India submerged with the infection of cumulative infection 100 to 500. The country office of the World Health Organization (WHO) of India declared its safety concerns to the citizens and foreigners on preparedness to respond to their suggestions against this catastrophe (Lauer \& 
Grantz, 2020). National service on disease control was performed their preparedness on state-based awareness by social media and electronic media. The joint monitoring group of emerging diseases was attempted regular meetings with the health ministry and officials to submit a daily report on the COVID 19 scenario at every state level (Bukhary \& Jameel, 2020). Indian Council of Medical Research proposed a lot of antiviral, anti-malaria, antibacterial drugs supportive to cure this viral affection. Transfusion on blood therapy was proposed to cure patients by authentication of sera-diagnosis (Ananthanarayan \& Panikhar, 2013) such as plasma therapy for infected from cured, $\operatorname{IgG}$ determination by Enzyme-Linked Immune Sorbent Assay, and the highest level is practiced on Real-Time PCR. The disaster infections were descended from Wuhan in China, December 2019. India became with the selected carrier host who was first detected in January 2020 at Kerala emigrated by air flight from China (Das, 2020). The spreading number of infected were attached in a huge volume at a dense population of a particular place, sporadically leads the COVID 19 disaster. According to the diverse population size in different states of India, the sporadic affection took place at a different rate of spread by mutant and non-mutant strains isolated 11 mutant strains from Bengaluru. Following an example, it was clearly stated that the infection rate of Maharastra (Cumulative case 2500 per day) was higher than the west Bengal (Cumulative case 300 per day), reported on $16^{\text {th }}$ April 2020 (Das, 2020). The infection rate was proliferated following the semi curve from infected to contact individuals. Then after migrated from subclinical to clinical state (Cohen \& Nomile, 2020), the chronicles of the catastrophic were ranged in high risk by the cumulative performance of increasing thousand to millions (Tang et al., 2020a). Epidemiological studies regarding viral disease transmission are so quite impossible to describe. But the impact of the COVID 19 scenario is different (Chen et al., 2020b). The migration of the virus is prolonging its chain by mutant and non-mutant forms. Now uttermost seventy-three strains were described deriving from the mutant and nonmutant form. So, vaccines (monovalent, divalent, trivalent, tetravalent, and polyvalent) in the future are not assured to apply to control this disease disaster (Gumel et al., 2004). The government of India including different states part estimated the percentage rate and trying to control it by their efforts. But the impossible task should have to hands cape by controlling management, epidemiological knowledge, and implementation of viral disease prevention with initiative measures. The extremity of preventive measures is applied to ensure lockdown following for prevention mass gathering in an overpopulated area (Drosten et al., 2003). Two approaches were proposed as a model to find out actual lockdown periods and other measures of prevention despite the route of an outbreak (Zhou \& Gates, 2020).

The present study is focused on two models suggesting that the quarantine period should be 21 days and the lockdown period should have to follow up to 111 days in India based on population and morbidity size. These models can also be executed in newly COVID-affected countries or provinces of any part of the world.

\section{Materials and Methods}

The explained model is established by collecting numerical strata of infected individuals on random selections from daily reporting of Health ministry, India. Data from daily reports were assessed from trusted media of online organizations. Classifying of collected data on different zones is to have a view of diagrammatic figure accomplishing proposed models one, two, and three (combined reformed model one and two for sporadic transmitted population). Data were set up to follow a model that was clarified into four groups of individuals. Then the clarifications were sustained on various steps such as lockdown, risk factors, isolations, quarantines, herd immunity, and recovery percentages among the populations. The initials for beginning epidemiological studies were referred to as an integrated value known as $\mathbf{R}_{0}$ (Anderson et al., 2020). The reproduction factors of contagious transmission represented the model designing with some numbers of populations from a susceptible to infected class. Respected a particular asymptomatic population on a chain of transmission can be shown $\mathrm{R}_{0}$ less than 1 . But gradually increasing from infected to contact by symptomatically, the value would be $R_{0}=1$. The breakthrough of the uncontrolled proliferation of viral transmission leads the semilunar curve by designing the data model which referred to $\mathrm{R}_{0}$ greater than 1 (Wu et al., 2020). So the methodology is developed a following-

\subsection{Methodology on Statistical models to analyze data}

The described models were followed (Das, 2020) to derive the equation of statistical incidence value. The incidence rate is calculated in two different ways from epidemiological and statistical, meant for two ways of tabulated calculations by exposed and non-exposed populations.

\subsection{Methodology on Epidemiological models to analyze data}

This is the first time; models are proposed on an epidemiological basis to describe the solutions to solving viral transmission from this catastrophe. There is no evidence of published diagrammatic models on epidemiology-based to inhibit the growing chain of viral transmission. A lot of mathematical models were established by theorem but not diagrammatic viewed for solving to develop herd immunity process from infected populations.

The successive implements of models depend on its population size, the incident rate of infections, and the marginal rate of infected people, then finally morbidity, the mortality rate of disease clusters, and the hotspots zone (Figure 1). These models 
are flexible enough to modulate internally if any planner can change them for better outcomes by studies (Figure 1). Diagrammatic Model one is followed in almost every country that COVID 19 is affected. And model two is the architect views of epidemiological studies for prevention to control disease disaster signified on proper management, disease handler, and tracing of contacted persons. The eradication is completely studied in these models from a part of epidemiology and community medicines by developing herd immunity and vaccination to forward initials on the beginning (Figure 1). An example is based on South Korea that proved 163 patients recorded positive after getting a cure by their health authorities.
2.3 Methodology on Tentative and confirmatory diagnosis to analyze models

\subsubsection{Rapid Antigen Test (Sanjuan et al., 2010)}

The SARS-CoV 1 was very significantly diagnosed from migratory birds in examined with the titer concentration of antigen-antibody level. The modified technique is improvised for viral transmission as a form of zoonoses in the modified device. Now different antigens and serotypes from different antibodies are framed in a device to detect in rapid and accurate methods.

\section{Proposed Model 1: Isolation and Quarantine}

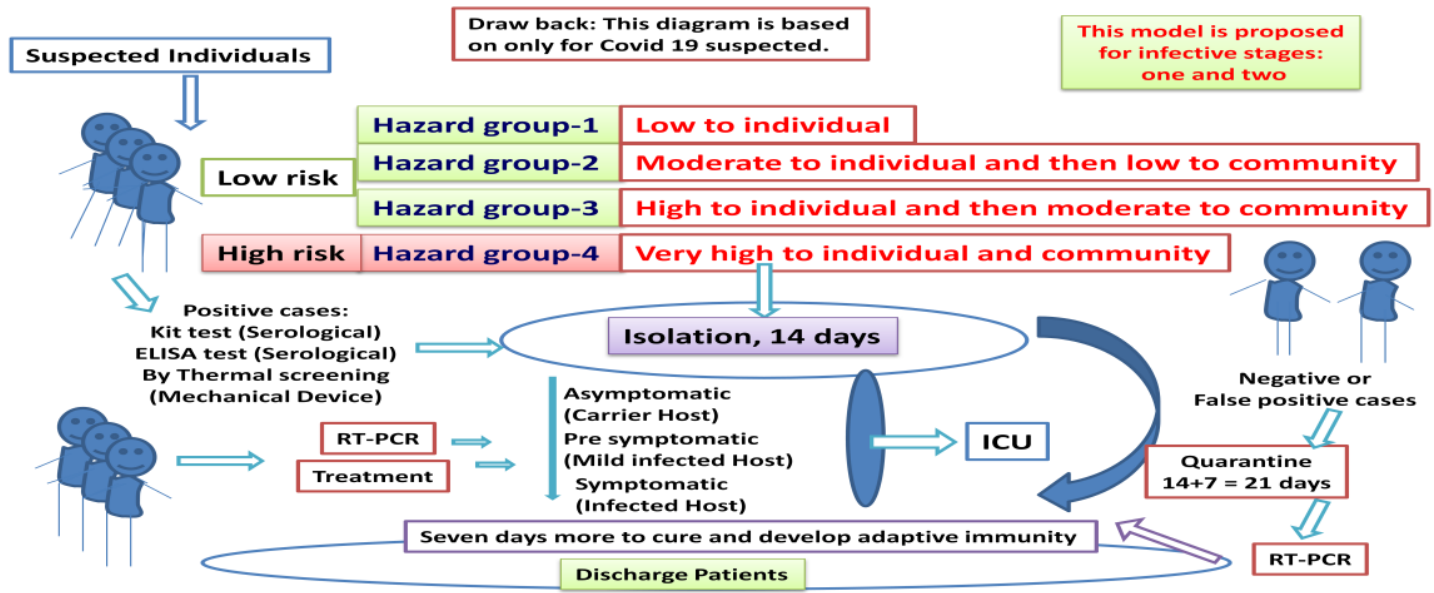

Figure 1 Diagrammatic model is determined for following primary steps for isolations and quarantine to infected and contacted individuals by SARS-COV 2 infections
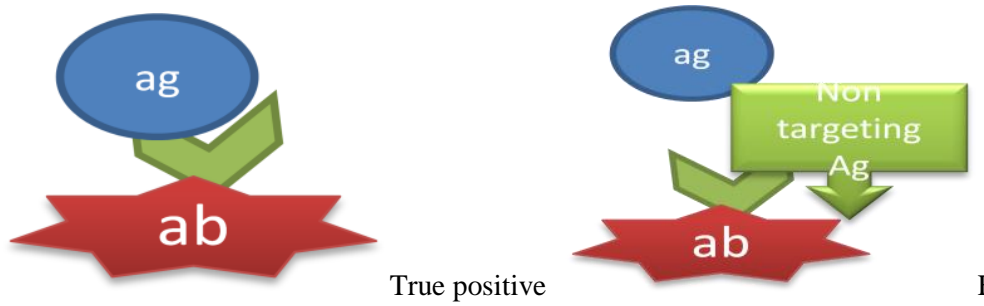

False positive

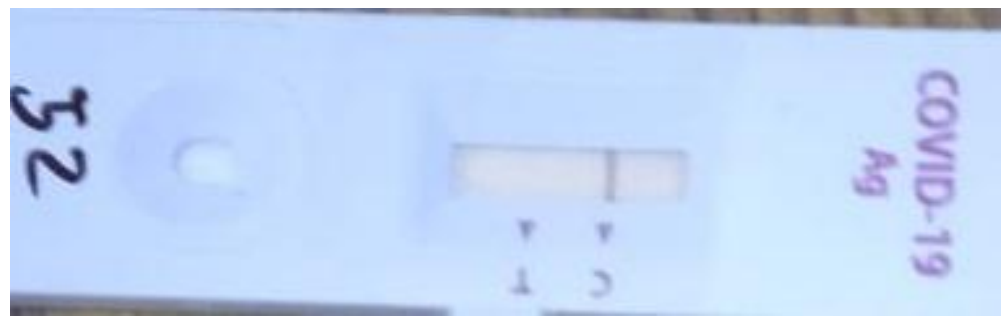

Figure 2 The Rapid Antigen Test is performed to detect the instant result of suspected Covid patients for presumptive diagnosis

(Positive: Clumping occurred between target antigen and specific antibodies; Negative: Absent of clumping; False-positive:

Clumping occurs between non-target antigen and specific antibodies; False-negative: Clumping is absent due to a mismatch of detection for the presence of secondary antigen between target antigen-specific antibodies)

Journal of Experimental Biology and Agricultural Sciences

http://www.jebas.org 
Rapid tests are designated to design for use where a preliminary screening test result is required especially useful in checking antigen-antibody reaction in support limited settings. This test principle is followed by four types of reports for affected and nonaffected populations. Clumping is diagnosed between target antigen and specific antibodies (Figure 2).

So reported third and fourth are very vital to play a role in the isolation of non-infected treating as infected and infected will be free as non-infected in a population or community. This unreliable job should be clarified before implementation.

\subsubsection{Convalescent Plasma Therapy (ICMR, 2020)}

Convalescent plasma therapy is the diagnostic procurement of a patient by confirming antigen-antibody titer determination by a screening of hemopoietic cells of plasma before and after infection. Plasma from a cured patient after 21 to 28 days of infection from COVID 19, and then transfusion to infected patients. The steps are followed to proceed for adaptations by the checking of antibody titer including serotype in recipient serum required to test sensitivity and susceptibility of plasma concentrations. The types of hypersensitivity of a recipient are screened considering his age, blood group, and secondary multiple diseases. Mechanisms of this technique is as follows:

SARS-CoV2 virus in lungs $\rightarrow$ Pulmonary circulate is occurred (Primary viremia) $\rightarrow$ General circulate (Secondary viremia) $\rightarrow$ Viruses meet up with donor antibodies. $\rightarrow$ Plasma concentration increases $\rightarrow$ Decreased concentration of viremia $\rightarrow$ Patient gets cured gradually.

\subsubsection{IgG Test by ELISA (ICMR, 2020)}

In simple terms, ELISA is defined unknown amount of antigen, affixed to a surface, and then a specific antibody washing over the surface. So that it can be bind to the antigen. This antibody is linked to an enzyme, and in the final step, a substance is added that the enzyme can convert to some detectable signal. The IgG antibody method of the Sandwich ELISA (Unknown antigen and known antibodies) technique is developed for SARS CoV2 RNA detection. For this, $1 \mathrm{ml}$ diluents with 10 microlitre serum are mixed for the selective solution to diagnosis. 100 microlitres mixed solution in good strip to shake and blot on absorbent. Then the addition of 300 microlitre wash buffer is selected for washing following four times. The next step is preceded by adding 100 microlitre conjugate which should be covered by a protective film for 15 to 45 minutes. The next forwarded addition of 300 microlitre wash buffer is followed to wash again four times. Then the concentrated 100 microlitre TMB substrate is added and covered by protective film kept for 10 to 15 minutes, stop solutions of 100 microlitres are being concentrated to add for developing color. Color is screened for positive by spectrometer reading and checked for outcomes. (N.B: An outline of a protocol is sketched but it may differ on different companies, Manuel).

\subsubsection{Molecular diagnosis (ECDC, UK, 2020)}

The genomic migration occurs spontaneously for the variants to infect in such a transmission series. The launched vaccine trial is considered with checking antigen-antibody titer level to increase their potency for nuclear-derived molecular diagnosis. The aspect of molecular diagnosis is the background from microbial genetic detection. The conventional polymerase chain reaction technique is amplified to label with some special markers of viral rdbp transcript of sequences (Arena et al., 2021).

Real-time PCR is designed as a nuclear-derived molecular diagnosis for detecting the presence of microbial genetic material including viruses. The method is established using radioactive isotope markers representing the genetic materials, by isotoping labeling with special markers of fluorescent dyes. This technique is implemented widely and now current results are very much prolific to diagnose in current trends or infected patients. The technique is as follows:

Blood or sputum $\rightarrow$ RNA extraction $\rightarrow$ c DNA $\rightarrow$ Amplified by specific primer $\rightarrow$ Real-Time PCR $\rightarrow$ Ciber green dye molecule changes the fluorescence label binding with DNA $\rightarrow$ PCR cycle amplified with a signal of fluorescence positive $\rightarrow$ Control compared with infected samples of the E protein and rdbp transcript label. $\rightarrow$ Infected level increased $\rightarrow$ Viral m RNA detected $\rightarrow$ Suspected person is positive.

These two models are suggested that the quarantine period should be 21 days and the lockdown period should have to follow up to 111 days in India based on population and morbidity size (Figure 3). These models can be implemented in newly COVID-affected countries or provinces of any part of the world. Mizoram is already been declared to follow 21 days quarantine period that was mentioned by the model before two months (Figure 3).

Example: This diagram is showing the classified fields of the proposed model to implement for the COVID affected of 9.6 million populations in an urban area that chronologically affected (Figure 3). Each area should maintain proper lockdown days with an interpretation of newly infected persons and proper tracing of their contact individuals (Figure 3). The following work should maintain in data-based validation to update the present scenario within this particular COVID19 area (Figure 3). Schedule records are preserved to have a chart on asymptomatic, co-morbid, or morbid patient screening out for cured individuals (Figure 4).

Prediction of Model is compared with Indian Government Technocrat: Recently technocrats of India accomplished their 90 
days lockdown and followed their strategy on unlocking in slower steps developing herd immunity against the viral transmission. But this strategy disassociated with the daily infection rate leading highest between the contacts and infected. And the raised curve is increasing every day following the upper limit of 16000 (Reported data from $1^{\text {st }}$ to $10^{\text {th }}$ June 2020). The statistical prediction of the model is recommended for 111 days lockdown in COVID 19 affected area which may lead to the upper limit on 10000 individuals to infect per day of unlocking.

Models were described and rectified on following ICMR updates and proposed protocols for COVID hospitals, patients, and awareness programs. The propagated number of strata was counted from $1^{\text {st }}$ March 2020 to $5^{\text {th }}$ July to verify their protocols along with proposed models. ICMR deals with a lot of updated performances that played an important role in the Indian Health Sector from diagnostic to vaccine development.

\subsection{Methodology of Implemented data on proposed Models}

Indian SARS-CoV-2 Consortium of Genomics recently forecast the double mutant of variant named as B.1.617, that contains and designed with two mutants E484Q and another is L245R. Though the studies are under ways to be described and considered in these

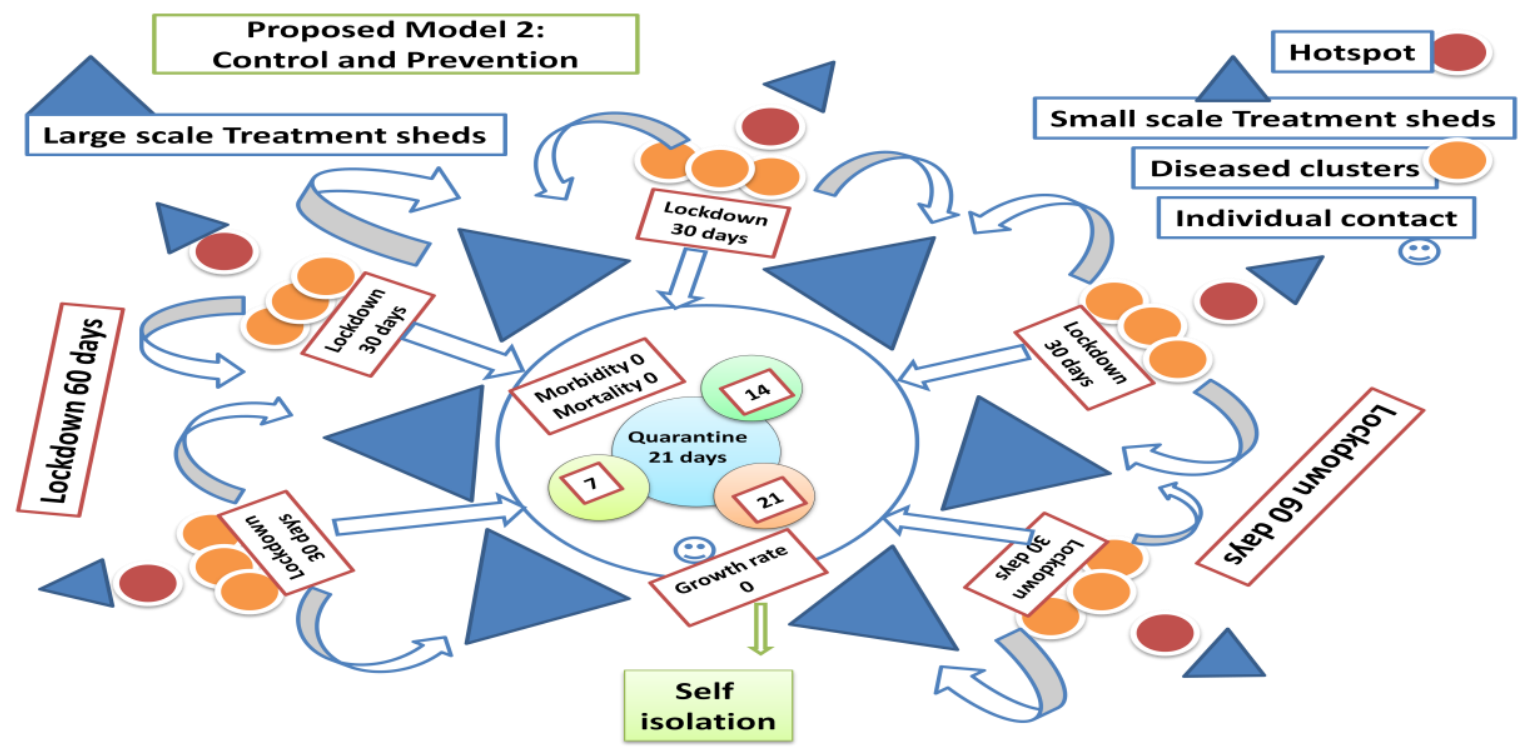

Figure 3 Diagrammatic model is viewed on focusing the disease disaster management following 111 Days lockdown schedule segmented in a different pattern of confinement zones.

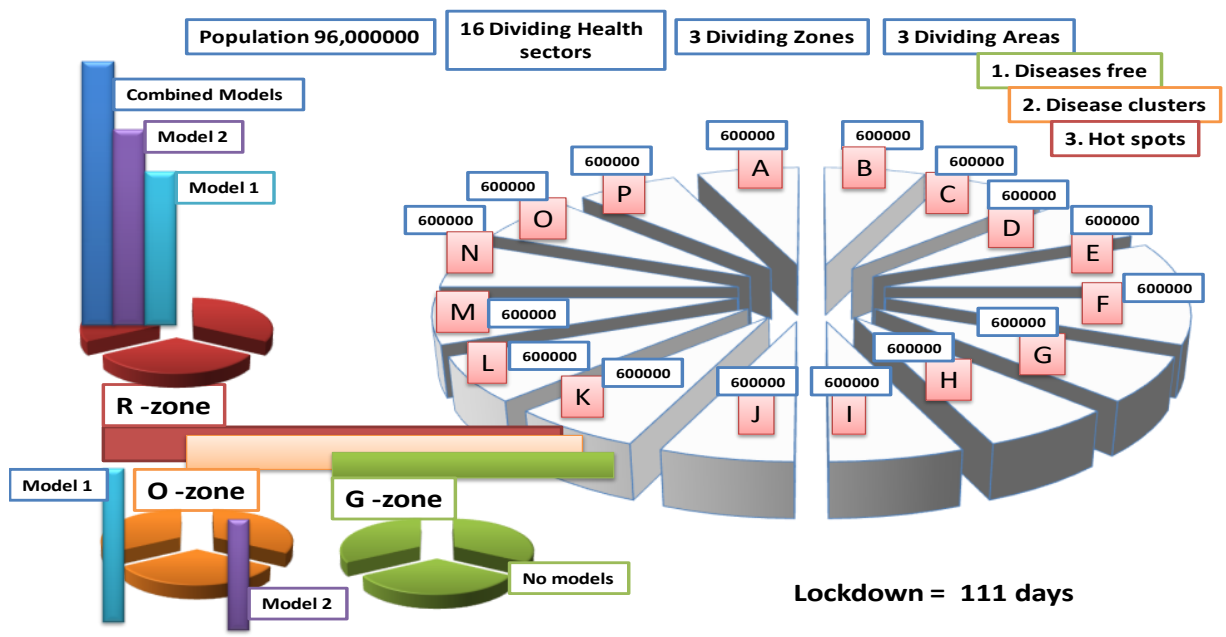

Figure 4 Diagram is showed the classified fields of the proposed model to implement for the COVID 19 area of infected populations as an example

Journal of Experimental Biology and Agricultural Sciences http://www.jebas.org 
models to control. The proposed model can play a significant role in the current month of exponential rise at vital wave tides in high morbidity with less mortality and less immunized populations. The proposed model should be clarified into the different units before studies. The successive implements of models depend on its population size, the incident rate of infections, and the marginal rate of infected people, then finally morbidity, the mortality rate of disease clusters, and the hotspots zone (Figure 5). Availability of medical pieces of equipment, protective and safety types of equipment for doctors and disease handlers, minimum expenditure in reliable cost should be considered before planned to apply.

\section{Results}

The previous model that is associated with mathematical expression is to determine the tress out the infection rate from a particular population. Das (2000) was implemented to design a new model by the estimation of basic case counts in India. The model was discussed in the following SIS (Susceptible Infectious Susceptible) model for their analysis of prediction. The sources of

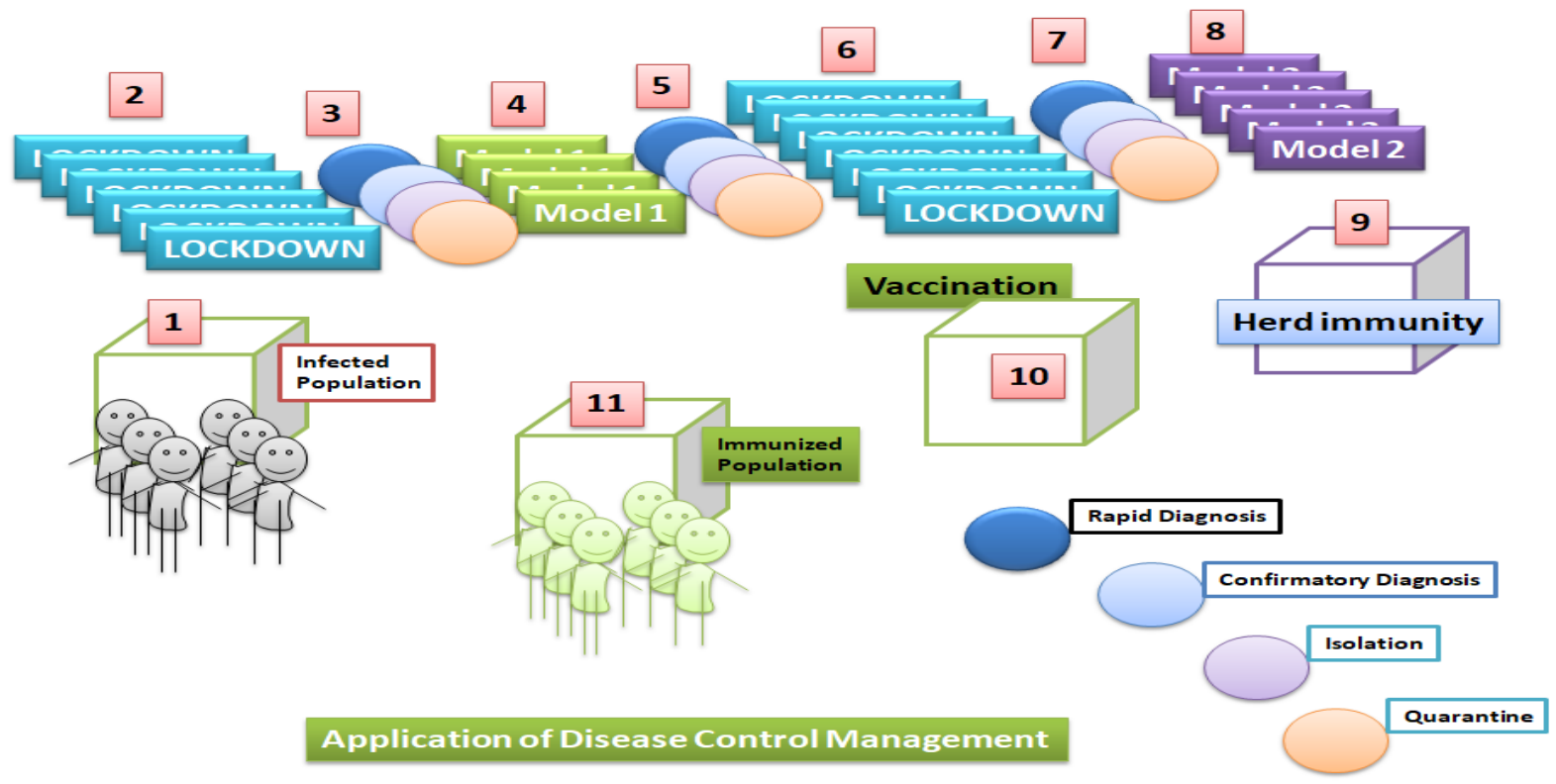

Figure 5 Effects of the proposed model are diagrammed on its impacts after coordination with the infected population to develop herd immunity

Table 2 Statistical calculation on incidence risk values: (following after 90 days lockdown)

\begin{tabular}{|c|c|c|c|c|c|}
\hline $\begin{array}{c}\text { Confirmed Case } \\
\qquad\left(\mathrm{X}_{1}\right) \\
\text { Mean values }\end{array}$ & $\begin{array}{c}\text { Active Case }\left(\mathrm{X}_{2}\right) \\
\text { Mean values }\end{array}$ & $\begin{array}{c}\text { Recovered Case } \\
\left(\mathrm{X}_{3}\right) \\
\text { Mean values }\end{array}$ & $\begin{array}{c}\text { Deceased Case }\left(\mathrm{X}_{4}\right) \\
\text { Mean values }\end{array}$ & $\begin{array}{c}\text { Incidence } \\
\text { Risk, } \\
\mathrm{R}_{0(\mathrm{G})}=\mathrm{X}_{1}-\mathrm{X}_{3} / \mathrm{X}_{1} \text { (Non } \\
\text { exposed population) }\end{array}$ & $\begin{array}{c}\text { Incidence } \\
\text { Risk, } \\
\mathrm{R}_{\mathrm{E}(\mathrm{G})}=\mathrm{X}_{2^{-}} \\
\mathrm{X}_{4} / \mathrm{X}_{2} \\
\text { (exposed } \\
\text { population) }\end{array}$ \\
\hline $\begin{array}{c}13368384 / 31 \\
=43,1,238.1935\end{array}$ & $\begin{array}{c}5481058 / 31 \\
=176808.3226\end{array}$ & $\begin{array}{l}7296266 / 31= \\
235363.4194\end{array}$ & $384503 / 31=12403.3225$ & 0.45 or $45 \%$ & $\begin{array}{c}0.92 \\
\text { or } 92 \%\end{array}$ \\
\hline
\end{tabular}

Table 3 Data model for epidemiological analysis.

\begin{tabular}{|cccc|}
\hline Observations & Diseased & Diseased free & \\
\hline Contact & $\mathrm{C}$ & $\mathrm{D}$ & $\mathrm{C}+\mathrm{D}$ \\
\hline Exposed free & $\mathrm{E}$ & $\mathrm{F}$ & $\mathrm{E}+\mathrm{F}$ \\
\hline Count & $\mathrm{C}+\mathrm{E}$ & $\mathrm{D}+\mathrm{F}$ & Total= C+D+E+F \\
\hline
\end{tabular}

The calculation is set up by for exposed population, odds $=\mathrm{C} / \mathrm{D}$; And for exposed free populations, odds = E/F; Exposed risk of incidence $=\mathrm{C} / \mathrm{C}+\mathrm{D} ;$ Non exposed risk of incidence $=\mathrm{E} / \mathrm{E}+\mathrm{F}$; Risk at incidence in the total population $=\mathrm{C}+\mathrm{E} / \mathrm{C}+\mathrm{D}+\mathrm{E}+\mathrm{F} ; \mathrm{Estimation}$ of ratio in risk $=(\mathrm{C} / \mathrm{C}+\mathrm{D}) /(\mathrm{E} / \mathrm{E}+\mathrm{F})$.

Journal of Experimental Biology and Agricultural Sciences http://www.jebas.org 
data were one based to design the incidence value on calculations by resumed SIR (Susceptible Infectious Removed) for their analysis and prediction. The newly proposed epidemiologicalbased model is decorated by collecting data from a particular infected population from Indian COVID 19 scenarios.

The tabulated data is signified for implemented modulation on statistical analytics, to determine the actual mean and percentages of significance required to construct the proposed model (Table 1). The data are assembled on the distribution in a series to explain the different aspects of epidemiology and bio-statistics. The report is assured from sources of daily infected rate acting on profiled values of confirmed cases, active cases, decreased cases, and tested cases. The incidence risk in non-exposed and exposed populations varies on average 45 to 92 percent showing the near about the highest peak of infection rate (Table 2). The epidemiological analysis and the analysis of variance (Table 3, 4, \& 5) are plotted to justify the efficacy of the model, showing the no significant variations are determined against the proposal (Table $5 \&$ Table $6)$.

Table 1 Data obtained from $5^{\text {th }}$ June to $5^{\text {th }}$ July 2020 to determine Mean from the series of 31 days (source: covid19india.org)

\begin{tabular}{|c|c|c|c|c|c|}
\hline Date & Confirmed Case & Active Case & Recovered Case & Deceased Case & Tested Case \\
\hline $5 / 6 / 2020$ & 236191 & 116306 & 113224 & 6647 & 4524317 \\
\hline $6 / 6 / 2020$ & 246599 & 120982 & 118657 & 6944 & 4666386 \\
\hline $7 / 6 / 2020$ & 257481 & 126412 & 123848 & 7205 & 4774434 \\
\hline $8 / 6 / 2020$ & 266017 & 129504 & 129019 & 7476 & 4916116 \\
\hline $9 / 6 / 2020$ & 275998 & 133579 & 134653 & 7748 & 5061332 \\
\hline $10 / 6 / 2020$ & 287154 & 138102 & 140928 & 8106 & 5213140 \\
\hline $11 / 6 / 2020$ & 298289 & 142792 & 146972 & 8500 & 5363445 \\
\hline $12 / 6 / 2020$ & 309595 & 146447 & 154235 & 8888 & 5507182 \\
\hline $13 / 6 / 2020$ & 321634 & 150072 & 162326 & 9197 & 5658614 \\
\hline $14 / 6 / 2020$ & 333038 & 153792 & 169684 & 9521 & 5774133 \\
\hline $15 / 6 / 2020$ & 343070 & 152786 & 180323 & 9917 & 5921069 \\
\hline $16 / 6 / 2020$ & 354155 & 154640 & 187549 & 11921 & 6084256 \\
\hline $17 / 6 / 2020$ & 367263 & 160517 & 194439 & 12262 & 6249668 \\
\hline $18 / 6 / 2020$ & 381092 & 163261 & 205180 & 12605 & 6426627 \\
\hline $19 / 6 / 2020$ & 395832 & 168604 & 214209 & 12969 & 6616496 \\
\hline $20 / 6 / 2020$ & 411750 & 170239 & 228183 & 13277 & 6807226 \\
\hline $21 / 6 / 2020$ & 426901 & 175889 & 237258 & 13703 & 6950493 \\
\hline $22 / 6 / 2020$ & 440461 & 178258 & 248137 & 14015 & 7137716 \\
\hline $23 / 6 / 2020$ & 456117 & 182980 & 258599 & 14483 & 7352911 \\
\hline $24 / 6 / 2020$ & 472985 & 186335 & 271688 & 14907 & 7560782 \\
\hline $25 / 6 / 2020$ & 491190 & 190156 & 285671 & 15308 & 7776228 \\
\hline $26 / 6 / 2020$ & 509445 & 197783 & 295917 & 15689 & 7996707 \\
\hline $27 / 6 / 2020$ & 529587 & 203282 & 310146 & 16103 & 8227802 \\
\hline $28 / 6 / 2020$ & 549197 & 210877 & 321777 & 16487 & 8398362 \\
\hline $29 / 6 / 2020$ & 567536 & 215298 & 335274 & 16904 & 8608654 \\
\hline $30 / 6 / 2020$ & 585792 & 220478 & 347839 & 17409 & 8826585 \\
\hline $1 / 7 / 2020$ & 605221 & 227405 & 359903 & 17847 & 9056173 \\
\hline $2 / 7 / 2020$ & 627168 & 228975 & 379902 & 18225 & 9297749 \\
\hline $3 / 7 / 2020$ & 649886 & 236832 & 394319 & 18669 & 9540132 \\
\hline $4 / 7 / 2020$ & 673904 & 245493 & 409065 & 19280 & 9789066 \\
\hline $5 / 7 / 2020$ & 697836 & 253162 & 424891 & 19700 & 9789066 \\
\hline
\end{tabular}

Journal of Experimental Biology and Agricultural Sciences http://www.jebas.org 
From tabulated data, the bio-statistical method was implemented for the calculation of the means of each column. The calculated mean was followed and compared with mid values of assembling represented categorized data. Furthermore, the lockdown period was observed following the Government of India to reconstruct the incidence rate from statistical calculations.

\subsection{Statistical calculation on incidence risk values (following} after 111 days lockdown according to proposed models)

Indian government followed the schedule for 90 days, whereas the model suggested 111 days. So the difference took (111-90) or 21 days more. So according to the model, the incidence risk of India would be $=0.45 \times 21 / 90=0.105$, so for 111 days lockdown,

$\mathrm{R}_{0(\mathrm{M})}=0.45-0.105=0.345$ or $34.5 \%$ and $\mathrm{R}_{\mathrm{E}(\mathrm{M})}=0.92-0.214=$ 0.706 or $70.6 \%$

Association of exposures (risk factors) and outcomes are studied by an analytical parameter arranged alphabetically. Measuring a table from an estimated population where individuals are subjected as disease-free in a particular period.

The exposures of contact and newly infected are concerned for studies as parameters monitored for a diseased population at a particular time. The values are followed to be a prediction on binary variables arranged in the format of a $2 \times 2$ table as explained in Table 1.

Table 4 Epidemiological calculation following after 90 days lockdown

\begin{tabular}{|cccc|} 
Observations & Diseased & $\begin{array}{c}\text { Diseased } \\
\text { free }\end{array}$ & Total \\
\hline \multirow{2}{*}{ Exposed } & $\mathrm{a}=$ & $\mathrm{b}=$ & $\mathrm{a}+\mathrm{b}=$ \\
& $43,1,238.1935$ & 176808.3226 & 608046.5161 \\
\hline \multirow{2}{*}{ Exposed free } & $\mathrm{c}$ & $\mathrm{d}=$ & $\mathrm{c}+\mathrm{d}=$ \\
& $=235363.4194$ & 12403.3225 & 247766.7414 \\
\hline \multirow{2}{*}{ Count } & $\mathrm{a}+\mathrm{c}=$ & $\mathrm{b}+\mathrm{d}=$ & $\mathrm{n}=$ \\
& 666601.6129 & 189211.6451 & $\mathrm{a}+\mathrm{b}+\mathrm{c}+\mathrm{d}=$ \\
& & & \\
\hline
\end{tabular}

Estimation of calculated values

Incidence risk in the exposed population: $\mathrm{R}_{\mathrm{E}(\mathrm{G})}=\mathrm{a} / \mathrm{a}+\mathrm{b}=0.7092$ Incidence risk in the non-exposed population: $\mathrm{R}_{0(\mathrm{G})}=\mathrm{c} / \mathrm{c}+\mathrm{d}=$ 0.9499

\subsection{Epidemiological calculation following after 111 days lockdown accordance with models}

Indian government followed the schedule for 90 days, whereas the model suggested 111 days. So the difference took (111-90) or 21 days more. So according to the model, the incidence risk of India would be $=0.94 \times 21 / 90=0.21$, so for 111 days lockdown,
$\mathrm{R}_{0(\mathrm{M})}=0.94-0.21=0.73$ or $73 \%$ and $\mathrm{R}_{\mathrm{E}(\mathrm{M})}=0.70-0.16=0.54$ or $54 \%$

Table 5 Enlisted data is used as a determinant to Analysis of variance.

\begin{tabular}{|cccc|} 
Observations & $\begin{array}{c}\text { Diseased } \\
\text { (Epidemiological } \\
\text { values from } \\
\left.\text { model: } \mathrm{R}_{\mathrm{E}} \text { and } \mathrm{R}_{0}\right)\end{array}$ & $\begin{array}{c}\text { Non-diseased or } \\
\text { survive } \\
\text { (Statistical values } \\
\text { from model: } \mathrm{R}_{\mathrm{E}} \\
\left.\text { and } \mathrm{R}_{0}\right)\end{array}$ & Total \\
\hline Exposed, $\mathrm{A}$ & $\mathrm{a}=0.54$ & $\mathrm{~b}=0.70$ & $\begin{array}{c}\mathrm{a}+\mathrm{b}= \\
1.24\end{array}$ \\
\hline Non- & $\mathrm{c}=0.73$ & $\mathrm{~d}=0.34$ & $\begin{array}{c}\mathrm{c}+\mathrm{d}= \\
1.07\end{array}$ \\
\hline exposed, $\mathrm{B}$ & $\mathrm{a}+\mathrm{c}=1.27$ & $\mathrm{~b}+\mathrm{d}=1.04$ & $\begin{array}{c}\mathrm{a}+\mathrm{b}+\mathrm{c}+\mathrm{d} \\
=2.31\end{array}$ \\
\hline Total, $\mathrm{C}$ & & & \\
\end{tabular}

Calculation of Analytics of Variance

Correction factor $=\mathrm{T}^{2} / \mathrm{N}=\left(\sum \mathrm{A}+\sum \mathrm{B}+\sum \mathrm{C}\right)^{2} / 9=(1.24+1.07+$ $2.31)^{2} / 9=2.3716$

Sum of squares of deviation for total variance

$=\quad 0.54^{2}+0.70^{2}+1.24^{2}+0.73^{2}+0.34^{2}+1.07^{2}+1.27^{2}+1.04^{2}+2.31^{2}$

Correction factor

$=12.1432-2.3716=9.7716$

Sum of squares of deviation for variance between samples

$=\left(\sum \mathrm{A}\right)^{2} / \mathrm{N}_{1}+\left(\sum \mathrm{B}\right)^{2} / \mathrm{N}_{2}+\left(\sum \mathrm{C}\right)^{2} / \mathrm{N}_{3}-$ Correction factor $=$ $(0.54+0.70+1.24)^{2} / 3+(0.73+0.34+1.07)^{2} / 3+(1.27+1.04+2.31)^{2} / 3-$ $2.37=(2.05+1.52+7.11)-2.37=8.31$

Table 6 Analysis of Variance (ANOVA) of proposed models

\begin{tabular}{|cccc|}
$\begin{array}{c}\text { Source of } \\
\text { variation }\end{array}$ & $\begin{array}{c}\text { Degree of } \\
\text { freedom }\end{array}$ & $\begin{array}{c}\text { Sum of the } \\
\text { square of } \\
\text { the } \\
\text { deviation }\end{array}$ & Variance \\
\hline Between verities & $3-1=2$ & 8.31 & 4.155 \\
\hline Within verities & $9-3=6$ & 1.4301 & 0.238 \\
& & & \\
\hline Total & $9-1=8$ & 9.771 & \\
\hline
\end{tabular}




\section{Estimation of significance}

Calculation of $\mathrm{F}_{1}$ value $=$ Greater variance $/$ Smaller variance $=$ $0.238 / 4.155=0.057$

Let us take the level of significance at $5 \%, \mathrm{~F}_{2}=5.1$ and in $1 \%, \mathrm{~F}_{2}=$ 10.9 (Degree of freedom for greater variance is six and Degree of freedom for smaller variance is two).

\subsection{Inference}

The calculated value of $F_{1}$ is less than the table value of $F_{2}$, noted for acceptance of the null hypothesis showing no significant difference in performance.

\subsection{Significance is viewed on graphical presentations}

The observational infected numbers are plotted following fifteen days tabulated as the data of infected individuals per day per population all over India. After 90 days of lockdown the incidence range was 15,000 per day per population, while according to the suggested lockdown period (111 days), the incidence range would be 10,000 per day per population in India after unlocking (Figure 6).

\subsection{Analytical and schematic comparison with mathematical proposed models}

\subsubsection{Exponential Model}

This model was established to show the exponential growth at the initial beginning. This mathematical model was furnished and formulated by differentiating calculus to measure the incidence rate from a population. The implement of the model was derived successfully during the Ebola pandemic in West Africa in 2014-15.

\subsubsection{Logistic Model}

The defined model was diagrammed and signified on the S-shaped curve or sigmoid curve determining the rate of growth of a pandemic (Lipkin \& Smith, 2000). The curve was studied by the population size, limitations of time, and sporadic parameters of infected persons. The infection rate was narrated on a platform of logical values of statistical calculations. So the meaning of this model is stood for implementation in mathematical concepts as in the following of the exponential model to prove.

\section{Significance:}
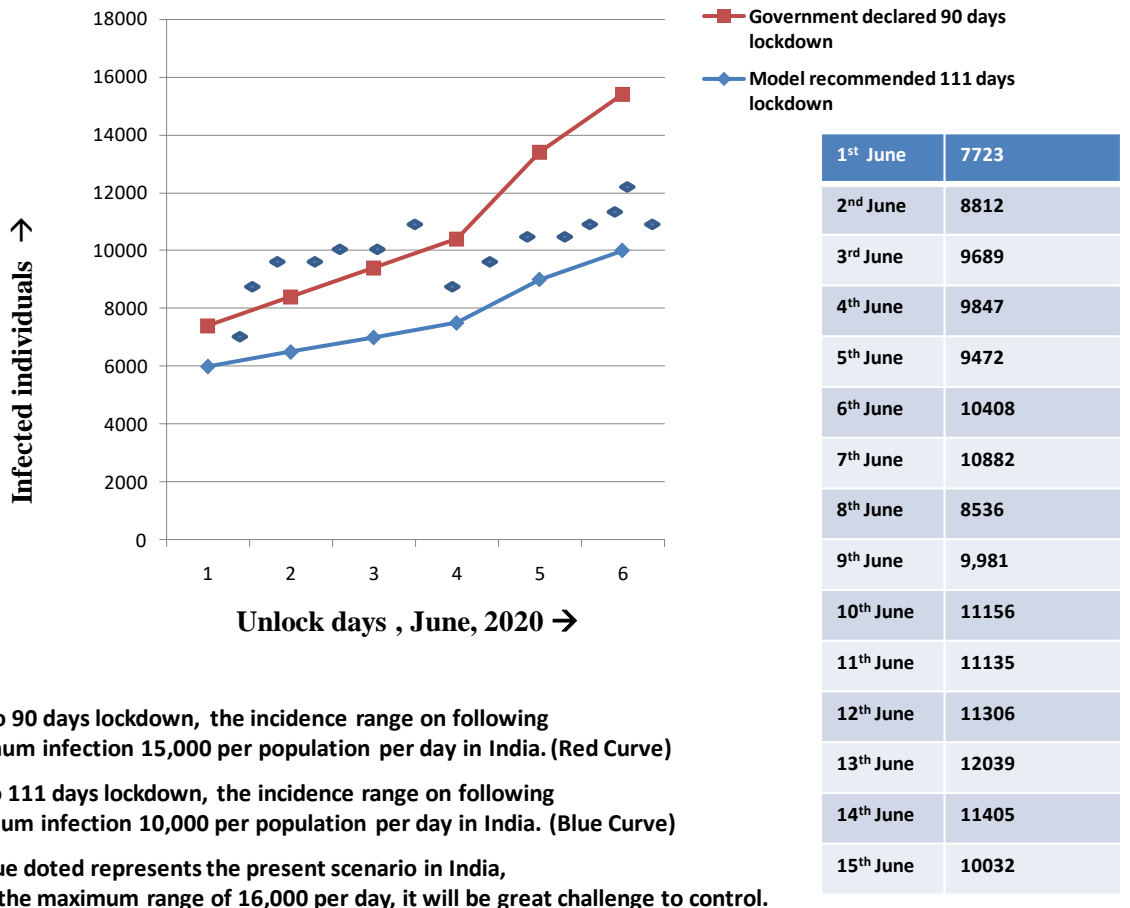
unlock leads the maximum infection 15,000 per population per day in India. (Red Curve)

According to 111 days lockdown, the incidence range on following unlock leads the maximum infection $\mathbf{1 0 , 0 0 0}$ per population per day in India. (Blue Curve)

Blue doted represents the present scenario in India, If the fluctuation displaces the maximum range of 16,000 per day, it will be great challenge to control.

Source: covid19india.org

Figure 6 COVID 19 growth curve graph on unlocking days are plotted to show a scenario of India from $1^{\text {st }}$ to $15^{\text {th }}$ June 2020. 


\subsubsection{Susceptible Infectious or Recovered model}

SIR model was augmented for a particular population for studying susceptibility to particular diseases (Kermac \& Mckendrick, 1927). The aim of this model is prone to be infected for a particular transmission of a community. This model plays an important role in mathematical dynamics captured the susceptible populations in a particular size of the area by the differentiation calculus model diagram (Table 7). The modified model from SIR is named SIS (Susceptible Infectious Susceptible model) conducted the range of incidence rate is portended on exponential logarithmic values of explanation (Table 7). Table 7 shows the comparisons of different implemented mathematical models and proposed models. of cases relatively represents the regulatory responses on plasma tested by inoculated vaccine by antigen-antibody titer per genetic information. Most of the vaccines act as less effective due to a mismatch with their vaccine efficacy and potency comparing with the titer of host body defense (Bhatnagar et al., 2020; Chen et al., 2020a). The morbidity rate is rather than more from mortality in March to onwards, 2021 (Bhatnagar et al., 2020). So, the models represent the design on an epidemiological feature of a pandemic version of 2020, but not modulated for variant epidemic 2021 (Wang \& Zhao, 2020). The systematic wave is concurrent flows from genetic mutations on the periphery to central spotted with high morbidity and less mortality. The unpredictable catastrophe in the present scenario of the world is following a high range of

Table 7 Comparisons are tabulated by the different implemented mathematical models and proposed models.

\begin{tabular}{|c|c|c|c|c|}
\hline Categories & $\begin{array}{l}\text { Exponential } \\
\text { Model }\end{array}$ & Logistic Model & SIR-Model & Proposed DAAM-Model \\
\hline Model theorem & Political Economy & Mathematical & Mathematical & $\begin{array}{c}\text { Statistical } \\
\text { and diagrammatic }\end{array}$ \\
\hline $\begin{array}{l}\text { Epidemiological } \\
\text { assessment of } \\
\text { incident values }\end{array}$ & $\begin{array}{l}\text { Population-based on } \\
\text { poverty }\end{array}$ & Mathematical & Mathematical & $\begin{array}{l}\text { Mathematical } \\
\text { and statistical }\end{array}$ \\
\hline Diagram & $\begin{array}{l}\text { Graphical on } \\
\text { demographic }\end{array}$ & $\begin{array}{l}\text { Graphical on } \\
\text { mathematics }\end{array}$ & $\begin{array}{l}\text { Graphical on } \\
\text { mathematics }\end{array}$ & $\begin{array}{c}\text { Dimensional } \\
\text { Monographic } \\
\text { And statistically graphical. }\end{array}$ \\
\hline $\begin{array}{l}\text { Mathematical } \\
\text { calculus }\end{array}$ & Explained & Explained & Explained & Non implemented \\
\hline $\begin{array}{l}\text { Epidemiological } \\
\text { analysis }\end{array}$ & Minor in mathematical & Minor in mathematical & $\begin{array}{c}\text { Minor in } \\
\text { mathematical }\end{array}$ & A major part of the discussion \\
\hline Analysis of variance & $\begin{array}{l}\text { Significant for a } \\
\text { particular population }\end{array}$ & $\begin{array}{l}\text { Significant for a } \\
\text { community } \\
\text { transmission }\end{array}$ & $\begin{array}{l}\text { Significant for } \\
\text { particular } \\
\text { population size }\end{array}$ & $\begin{array}{c}\text { Significant for a population of } \\
\text { pandemic and sporadic both } \\
\text { stages by statistical and } \\
\text { epidemiological } \\
\end{array}$ \\
\hline $\begin{array}{l}\text { Chance of } \\
\text { adaptability for viral } \\
\text { transmission }\end{array}$ & Approximate & Approximate & Approximate & Tentative \\
\hline $\begin{array}{c}\text { Field } \\
\text { implementation }\end{array}$ & Successive & Successive & Successive & $\begin{array}{c}\text { Still not have done, just } \\
\text { proposed }\end{array}$ \\
\hline
\end{tabular}

\subsection{Drawback}

The total outcomes continued for some drawbacks. These models are flexible enough to modulate internally if any planner can change it for better outcomes by the own studies of individuals.

Fruitful outcomes and significance are signified on proper management, disease handler, and tracing of contacted persons to minimize the exponential viral transmission rate from models one, and two.

\section{Discussion}

The global repository represents the number of simplified data track the currents emerging variants and strains. The huge number public health hazards. The transmissible chain of virus needs to break until any effective medicine or vaccine is launched (Wise, 2020). The schematic diagram of models one and two are proposed for controlling the transitive chain on a new concept. It is followed based on the exposure associated with disease frequency for prevention and control. The successive implements of models depend on its population size, the incident rate of infections, and the marginal rate of infected people, then finally morbidity, the mortality rate of disease clusters, and the hotspots zone. Diagrammatic Model one is followed in almost every country that COVID 19 is affected. And model two is the architect views of epidemiological studies for prevention to control disease disaster signified on proper management, disease handler, and tracing of contacted persons. The eradication is completely studied 
in these models from a part of epidemiology and community medicines by developing herd immunity and vaccination to forward initials on the beginning (Figure 1, 3, 5). These two models are suggested that the quarantine period should be 21 days and the lockdown period should have to follow up to 111 days in India based on population and morbidity size. These models can be implemented in newly COVID-affected countries or provinces of any part of the world (Figure 1, 3,6). The comparison part was analyzed by tabulated form showing the improvement to impeach the new model for viral transmitted infection rate among other mathematical models. The signified concerns assure to take part in the development of the socio-economic progress of India to protect the citizens from this catastrophic disease disaster. The continuous development of a model from differentiating analysis can play a lead role for further outcomes of the new concept on the biological concern. The discussed analysis predicted for population basis to control of initial steps in time to resist viral influences against civilizations.

\subsection{Prediction of Model is compared with Indian Government} Technocrat

The technocrats of India accomplished their lockdown period of 90 days and now their strategy is to follow on unlocking in slower steps developing herd immunity against the viral transmission (Tang et al., 2020b). But this strategy disassociated with the daily infection rate leading highest between the contacts and infected individuals (Wang \& Zhao, 2020; Wu et al., 2020). The raised curve was increasing per day following the upper limit of 16000 (Reported data from $1^{\text {st }}$ to $10^{\text {th }}$ June 2020) (Zhou \& Gates, 2020). The statistical prediction of the model is recommended for 111 days' lockdown in COVID affected area which may lead the upper limit on 10000 individuals to infect per day of unlocking (Table 1, 2,3)

Significance: Increasing rate of proper diagnosis $\rightarrow$ High percentages of cured individuals $\rightarrow$ Fewer mortality percentages $\rightarrow$ Developing a mass population for adaptive immunity $\rightarrow$ Adaptive immunity leads the herd immunity after 111 days of lockdown $\rightarrow$ Finally boosting vaccines to confirm immunized population to cure.

\subsection{Current trends on mutant variants}

While mutations occur in the coronavirus genomes, the key changes develop in spike protein. The variants (B.1.618) which carry some of the types and sub-types variants also been identified in the USA, Switzerland, Singapore, and Finland (Linda et al., 2021). The most common track of current mutations is associated with vaccine schedule and viability of immunization protecting the infected cell with increased infectivity and immune escape.

\section{Conclusion}

This novel Coronavirus plays an unpredictable role afterward implementations of the maximum range of vaccine trials and proper immunizations. Effective therapy like antiviral drugs or vaccination against SARS-CoV-2 is currently under assessment and progress. The only possible measure to control COVID-19 infection is prevention by diagrammed models, suggested in the current study of transmissive viral epidemiology, which has been designed to control SARS- CoV-2 spread. These models are flexible enough to modulate internally if any planner can change them for better outcomes by his studies. In today's world, environmental depletion is the major issue which in turn has decreased our lifespan, immunity power, etc. Being responsible citizens, let us contribute to save our nature, focus on sustainable development, and improve our lifespan and body immunity. It's time not to panic; it's time to fight together by following the preventive measures, lockdown, and quarantine among human society. Moreover, public health authorities of a COVID 19 infected area can be acted for following preventive and community medicinal way of treatment by this model till effective immunization is developed.

The proposed model should be clarified into the different units before studies to way out the center of the circumflex epidemic region. The successive implements of models depend on its population size, the incident rate of infections, and the marginal rate of infected people to estimate for proper management by government or social health care units. Therefore, in the present study, a schematic diagram of model one and two are proposed for controlling sporadic chain based on a new concept. The new concept is established based on the exposure associated with disease frequency for prevention and control to handle as a measured the estimated rate of infections. Availability of medical equipment, protective and safety equipment for doctors and disease handlers, minimum expenditure for reliable cost should be considered before planned to apply.

\section{Acknowledgment}

Sincerest and heartfelt gratitude to respected faculties Dept. of Botany, Gauhati University, and Dr. Saumitra Dey Choudhury, Ph.D., DBA, Scientist-II (AIIMS), New Delhi, India, for their cordial suggestions and meaningful advice to design the manuscript within a short time.

\section{Conflict of interest}

There is no conflict of interest to carry out this research model among all authors. 


\section{Funding statement}

This research work is not funded by any internal and external funding agencies.

\section{References}

ICMR Advisory on Strategy for COVID-19 Testing in India (2020) Recommended by the National Task Force on COVID-19 ICMR's advisory is generic in nature and may be modified as per the discretion of the state health authorities. VI: 1-4.

Ananthanarayan R, Paniker CKJ (2013) Text Book of Microbiology, $7^{\text {th }}$ edition, Orient Longman Private Ltd., Chennai, 2005.

Anderson RM, Heesterbeek H, Klinkenberg D, Hollingsworth TD (2020) How will country-based mitigation measures influence the course of the CoVID-19 epidemic?. The Lancet 395: 931-934. PMCID: PMC7158572DOI: 10.1016/S0140-6736(20)30567-5.

Arena F, Pollini S, Rossolini GM, Margaglione M (2021) Summary of the Available Molecular Methods for Detection of SARS-CoV-2 during the Ongoing Pandemic. International Journal of Molecular Sciences 22:1298.

Bhatnagar T, Murhekar MV, Soneja M (2020) Lopinavir/ritonavir combination therapy amongst symptomatic coronavirus disease 2019 patients in India: Protocol for restricted public health emergency use. Indian Journal of Medical Research 151(23): 184189. doi: 10.4103/ijmr. IJMR_502_20.

Bukhari Q, Jameel Y (2020) Will Coronavirus Pandemic Diminish by Summer?. Available at SSRN: https://ssrn.com/abstract=3556998 or http://dx.doi.org/10.2139/ssrn.3556998

Chen Y, Liu Q, Guo D (2020a) Emerging coronaviruses: Genome structure, replication, and pathogenesis. Journal of Medical Virology 92: 418-423. PMID:31967327PMCID:PMC7167049DOI:10.1002/ jmv. 25681

Chen T, Rui J, Wang Q, Zhao Z, Cui J, Yin LA (2020b) Proposed mathematical model for simulating the phase-based transmissibility of a novel coronavirus. Infect disease poverty 9 : 24. PMCID: PMC7047374DOI: 10.1186/s40249-020-00640-3

Cohen J, Normile D (2020) New SARS-like virus in China triggers an alarm. Science 367(6475):234-235. DOI: 10.1126/science. 367.6475 .234

Das S (2020) The CBD Dialectic in Mental Health: Benign and Powerful? Psychiatric Services 71(1): 2-3. doi: 10.1176/appi.ps. 201900394.
Drosten C, Gnther S, Preiser W, Werf S (2003) Identification of a Novel Coronavirus in Patients with Severe Acute Respiratory Syndrome. New England Journal of Medicine 348: 1967-1976. doi: 10.1056/NEJMoa030747.

European Centre for Disease Prevention and Control (2020) Rapid increase of a SARS-CoV-2 variant with multiple spike protein mutations observed in the United Kingdom. Source: TESSy, COVID-19 national weekly data. pp: 1-13. http://covid19-countryoverviews.ecdc.europa.eu/\#34_United_Kingdom.

Gumel AB, Ruan S, Day T, Watmough J, Brauer F, Driessche, PV, Gabrielson D (2004) Modelling strategies for controlling sars outbreaks. Proceedings of the Royal Society of London Series B 271:2223-2232. PMID:15539347PMCID:PMC1691853DOI: 10.1098/rspb.2004.2800.

Kermack WO, McKendrick AG (1927) A contribution to the mathematical theory of epidemics. The Royal Society. DOI: https://doi.org/10.1098/rspa.1927.0118.

Kumar S, Gosain M, Sharma H (2018) Social mixing insights from a rural population in India. PLOS ONE 13: 12. PMCID: PMC6303083 DOI: 10.1371/journal.pone.0209039

Lauer SA, Grantz KH, Bi Q, Jones FK, et al. (2020) The Incubation Period of Coronavirus Disease: Confirmed Cases: Estimation and Application. Annals of Internal Medicine 172(9): 577-582. PMCID: PMC7081172, DOI: 10.7326/M20-0504

Linda J, Carter VL, SmootWJ, LiY, Zhou Q, Saveson JC, Sasso JM, GreggAC, Soares DJ, Beskid TR, Jervey SR, LiuC (2021) Assay Techniques and Test Development for COVID-19 Diagnosis. ACS Central Science (6):591-605

Lipkin L, Smith D (2000) Logistic Growth Model. Convergence 2020: 1-3 http://www.maa.org/publications/periodicals/loci/ modeling-a-changing-world

Roosa K, Lee Y, Luo R (2020) Short-term Forecasts of the CoVID-19 Epidemic in Guangdong and Zhejiang, China. Journal of Clinical Medicine 9(2): 596. Doi: 10.3390/jcm9020596.

Sanjuan R, Nebot MR, Chirico N, Mansky L, Belshaw R (2010) Viral Mutation Rates. Journal of Virology 84(19): 9733-9748.

Tang B, Wang X, Li Q, Bragazzi NL, Tang S (2020a) Estimation of the transmission risk of the 2019-n COVID and its implication for public health interventions. Journal of Clinical Medicine 9(2): 462. PMCID: PMC7074281DOI: 10.3390/jcm9020462. 


\section{A Hypothetical Design to Inhibit COVID 19 Disease Disaster by Diagrammatic Model}

Tang B, Bragazzi NL, Li Q, Tang S, Xiao Y, Wu J (2020b) An updated estimation of the risk of transmission of the novel coronavirus (2019-n COVID). Infect diseases model 5: 248-255. PMCID: PMC7029158DOI: 10.1016/j.idm.2020.02.001.

Viboud C, Simonsen L, Chowell G (2016) A generalized-growth model to characterize the early ascending phase of infectious disease outbreaks. Epidemics 15: 27-37. DOI: 10.1016/j.epidem. 2016.01.002.

Wang Q, Zhao Z (2020) Clinical Characteristics of 138 Hospitalized Patients with 2019 Novel Coronavirus-Infected Pneumonia in Wuhan, China. The Journal of the American Medical Association 323 (11): 1061-1069.PMID:
32031570PMCID: PMC7042881DOI: 10.1001/jama.2020.1585.

Wise J (2020) Covid-19: New coronavirus variant is identified in UK. British Medical Journal. 2020: 371. doi: https://doi.org/ 10.1136/bmj.m4857.

Wu JT, Leung K, Leung GM (2020) Nowcasting and forecasting the potential domestic and international spread of the 2019-nCoV outbreak originating in Wuhan, China: a modeling study. The Lancet 395: 689-697. PMCID:PMC7159271DOI: 10.1016/S01406736(20)30260-9.

Zhou P, Gates P (2020) A pneumonia outbreak associated with a new coronavirus of probable bat origin. Nature 579: 270-273. PMCID: PMC7095418DOI: 10.1038/s41586-020-2012-7. 